\title{
Article \\ Sliding to Reverse Ableism: An Ethnographic Exploration of (Dis)ability in Sitting Volleyball
}

\author{
Carla Filomena Silva ${ }^{1, *}$ and P. David Howe ${ }^{2}$ \\ 1 School of Health Studies, Western University, London, ON N6A 3K7, Canada \\ 2 School of Kinesiology, Western University, London, ON N6A 3K7, Canada; david.howe@uwo.ca \\ * Correspondence: csilva42@uwo.ca
}

Received: 15 April 2019; Accepted: 15 May 2019; Published: 23 May 2019

\begin{abstract}
This paper illuminates the potential of diversely embodied sporting cultures to challenge ableism, the ideology of ability. Ableism constructs the able body as conditional to a life worth living, thus devaluing all those perceived as 'dis'-abled. This hegemonic ideology develops into a 'logic of practice' through a cultural appropriation of body's lived complexity, by reducing it to symbolic dichotomies (able/disabled). The path to challenge ableism is then to restore body's complexity, by turning attention toward its lived embodied existence. Drawing upon an ethnographic study of a sitting volleyball (SV) community, we condense multiple data sources into a sensuous creative non-fiction vignette to translate the physical embodied culture of the sport. In exploring SV physicality through the ethnographic vignette, it is our intention to activate the readers' own embodiment when interpreting and co-creating this text. By placing the reader in the lived reality of playing SV, we hope that the potential of this physical culture to destabilize engrained ableist premises becomes apparent. Ultimately, our goal is to promote a shift from ableism towards an appreciation and celebration of differently able bodies. This cultural shift is crucial for long lasting social empowerment for people with disabilities.
\end{abstract}

Keywords: ableism; ethnography; sitting volleyball; impairment; disability; habitus; situated action

\section{Introduction}

Modern sport originated from the desire to cultivate human perfection and physical, psychological, and moral excellence through the training and disciplining of the body [1]. Specifically, young adult male bodies. Individuals whose bodies were considered abnormal (such as female, aged, and impaired) did not really belong to the sports realm [2]. Although progress has been made with the inclusion of marginal bodies, all sporting cultures are inherently exclusionary because success in sport means physically beating the opposition. There is a belief entrenched in sporting rules, spaces, practices, social dynamics, and hierarchies that being able-bodied is both the normal and right way to be. This ableist logic configures "a network of beliefs, processes, and practices that produces a particular kind of self and body (the corporeal standard) that is projected as the perfect, species typical and therefore essential and fully human" [3] (p. 5).

While inclusion of 'disabled' participants is embraced by an increasing number of sporting cultures, it seldom entails a critical appreciation of what inclusion really means for the 'included'. When allowed to participate, usually in adapted versions of mainstream sports, individuals with 'less-than-able' bodies are judged for their ability to perform similarly to their 'normal' counterparts and not for their distinctive capabilities. This is why sport has failed so far to promote true empowerment for participants with impairments and trigger a long-lasting cultural shift regarding disability $[4,5]$. A more empowering alternative would be to respect everyone's unique embodiment and judge performance in accordance to such distinctiveness. 
The adapted sport at the center of this paper is sitting volleyball (SV). SV is distinctive from most disability sporting cultures since, within most national contexts, competitive and non-competitive, teams are open to players with a diverse range of embodiments, insofar as they can perform the foundational techniques of the sport. SV is a parasport in that it is part of the International Paralympic Committee's Paralympic Games program. Outside elite events, SV players with and without impairments play side-by-side, creating an environment of embodied diversity. In this paper we are interested in exploring whether this type of environment can challenge the ideology of ableism.

Focusing on the negotiation of embodied diversity in SV and its ideological implications, this paper illuminates understanding from a long-term ethnographic involvement of the first author in the SV community in England from October 2009 to September 2018. Such involvement has taken diverse forms: as a member of the extended technical support team for the women's GB squad (2009-2012); as a coach for regional teams (2010/11 and 2017/18), and as a player in the national grand prix competitions. Ethnographic data collected includes the lived experience of the game; observation and active participation in the SV community but also visual artefacts, semi-structured interviews with players, managers, officials, and volunteers as well as documentary evidence (media accounts, social media, and institutional documents).

For the purpose of this paper, large amounts of our data have been condensed into an ethnographic vignette, that is, a creative non-fiction account designed to give the reader a sensuous flavor of SV culture. This approach of synthesizing large amounts of data into a Weberian 'ideal type' has been used successfully in sport studies [6] and within the context of disability sport and leisure [7,8]. An analytical practice in itself, the aim of the ethnographic vignette is to 'show' this physical culture, rather than 'tell' it. The most significant event in the SV community, the national grand prix, is selected to showcase the multiplicity of embodied identities and voices shaping the SV community, whose actions and interactions in and out of the court illuminate both the constraints and opportunities within this culture to destabilize an ideology of ability. This type of text

Condenses the action in a tale that spans and adjusts time and place, revealing actual (witnessed) occurrences from within the period of data collection, but decontextualizing each occurrence and reorganizing in a way that reveals the lived experience in a less fragmented form [9], (p. 372).

The strengths and weaknesses of creative non-fiction have been explored elsewhere [10]. To us, creative non-fiction is the written representational form that best matches the openness and multidimensionality of a physical culture, while involving the reader, both emotionally and physically, in the interpretation/analysis of textual representations of this culture. Theoretically, creative non-fiction also prioritizes embodied movement as the focal object and subject of enquiry [11], because it allows the writer to evoke the sensuousness of the 'field' experiences so that the readers can imaginatively embody those experiences. In this research, embodied movement is not only explored as a significant cultural element; playing SV is also essential as an epistemological process so that the several sources and types of information can be interpreted from a position of embodied experience.

Before we turn to the ethnographic vignette, we outline the theoretical foundations of our research, exploring the premises and genealogy of ableism as presented within the field of disability studies. Marginal physical cultures, such as SV, provide a fertile ground for this investigation and Bourdieu's theory of practice $[12,13]$ assists in understanding how ableism becomes embodied in cultural practices. Shilling's pragmatic concept of situated action [14] offers a theoretical tool to appreciate how diversely embodied physical cultures, such as SV, can destabilize ableism.

Following the discussion of the theoretical lens employed, we recreate the culture of SV through the ethnographic vignette before offering analytical insights into how this distinctive sporting practice can help destabilize ableism. 


\section{Ableism: The Ideology of Ability}

We tend to rationalize individual differences in terms of diversity: "We are all unique". But when uniqueness transgresses the boundaries of normative acceptability, it is perceived as essential difference, and transforms into stigma. Specific characteristics such as visible impairments become markers of a "spoiled" existence [15]. The limits of acceptable difference are impossible to circumscribe, as these are historically and culturally dependent. Notwithstanding, this presence of stigma exposes the otherwise invisible and unstated norms generating it. When impairment is stigmatized, its able-bodied normative background surfaces, opening it to scrutiny.

Ableism, that is, the ideology of ability, constitutes a form of cultural imperialism, the "universalization of a dominant group's experience and culture, and its establishment as the norm" [16] (p. 59). The able-bodied experience is therefore constructed and disseminated as the impartial and natural "norm", which becomes the standard reference for the right and good way of being human. Against it, visible impairment (a 'brute' biological fact) is associated with dis-ability (an 'institutional' constructed fact) [17]. The possession of a specific impairment endows individuals with symbolic meanings of diminished abilities, vulnerability, and dependency. The functional limitations resulting from the impairment itself are magnified and disability becomes an identity marker, encompassing one's full existence. Disability is constructed as inherently negative; and people with impairments as deviant, as 'the Disabled' Others [18-21]. Yet, the real problem is not the impaired body, "the problem is the way normalcy is constructed to create the 'problem' of the disabled person" [19] (p. 24).

Focusing on ableism instead of disablism entails a significant philosophical choice. Ableism focusses on the root causes of disability oppression, whereas disablism addresses mainly its oppressive symptoms [22]. Ableism illuminates the need for a cultural shift: the acceptance of impaired bodies as valid and valuable expressions of human diversity. As ableism is premised upon a completely cultured symbolic body, stripped of its corporality; to revert this process it is then necessary to return to the lived experience of the primordial body. This ideology relies on two symbiotic elements: the able body norm (or 'normalcy') and the constitutional divide able/disabled, that is, the perception of a fundamental difference between "perfected naturalized humanity and the aberrant" [3] (p. 6). We now turn to the element of power that is central to ableism.

\section{The Genesis and Power of Ableism}

Against the backdrop of industrialization and capitalism and the consolidation of nation states, the development of modern science intensified in the nineteenth century. Statistics and medicine in particular developed the professional apparatuses to proclaim and legitimize normative truths about the human body and its capabilities, setting up normative descriptors for the average human being $[18,23-26]$. These normative truths legitimized the division of bodies into standard and non-standard, reinforced through several seemingly 'scientific' differentiation practices [23,27]. Following Latour (1993), Campbell [3] describes these as "purification" practices, in that they "create divides of ontological distinctions" ([3], (p. 7). In the case of ableism, its constitutional divide "posits two distinct and entirely clear ontological zones: disabled and able (normate)" ([3], (p. 8). The constitutional divide able/disabled is then instituted, upon the fabrication of a normative (able) body culturally accepted as natural and therefore remaining unmarked.

The dichotomic ordering of the citizens' bodies (able/healthy/fit and dis-abled/unhealthy/unfit) constituted an important political tool for the state-nations to discipline, order and ultimately, control their citizen's bodies [28-30]. The goal (akin to eugenicist goals), was the regulation of the deviant by the state [23]. Young [16] highlights how such dividing practices, still present today, largely reproduce the worldview of the most powerful social groups, perpetuating social and cultural hegemonies. Since these groups possess the power and the means to control the production and dissemination of knowledge, they create regimes of truth [31] to reinforce the validity of their ideological premises. It is not surprising then that the desirability of able-bodiedness is so deeply internalized by individuals with impairments $[3,32,33]$ that they feel compelled to emulate it [34]. This emulation may take the 
form of passing as ablebodied; disguising or hiding impairment; striving for a 'cure' or 'amelioration' and/or going to great lengths to 'overcome' disability [35].

Once a constitutional divide between able and disabled is firmly established, 'translation' processes, "mixtures between entirely new types of being, hybrids of nature and culture" [3], (p. 7) offer avenues for the deviant to "manage" their difference. Although these translation (i.e., standardizing) practices may seem empowering, they mainly expand opportunities to access the ableist world, without truly challenging it. In doing so, the distinctive experiences of people living with disability are once again invalidated, further strengthening the able-bodied norm.

Since ableism developed from the cultural objectification of impaired bodies, it can only be inverted through a return to the lived experience of the primordial body, trough the exploration and validation of the complexity of the lived embodied experiences of impaired bodies.

\section{A Return to the Experiential Primordial Body}

The scientized classification of citizens' embodiments into dichotomic binaries stripped them of their primordial existence. Once classified and signified culturally (i.e., male/female; healthy/unhealthy; able/disabled), the primordial, natural, sensuous, experiential living body disappeared: "a completely modern body becomes a completely cultured body, a body which is defined, indeed circumscribed by the inscriptions upon it of cultural discourses" ([36], (p. 279). The chaotic nature of the primordial body constituted such a threat to the stability and order aspirations of modern societies that it had to be obliterated. The effect of this annihilation is still present in contemporary society. Our identities are largely pre-defined by the cultural scripts ascribed to our bodies [37] regardless of the degree of difference from the norm [38].

Sport was and still is highly engaged in this cultural appropriation of the body, by objectifying and classifying it. Within sporting spaces, athletic bodies are regulated and controlled through differentiation practices similar to the ones mentioned above. Some examples are: the close reproduction of the Olympic sporting model within all dimensions of the Paralympic Movements, such as competitive organization and schedule; the existence and validation of bodily hierarchies, determined by how close/distant athletes are from the able-bodied norm [39,40]. This differentiation is also manifested in the way competitions are still structured by impairment categories (i.e., athletics, wheelchair basketball, and wheelchair rugby), reproducing a medical approach to disability. Although classificatory practices are the cornerstone of Paralympic sporting cultures, they are clearly an expression of the ableist power to classify, categorize, and include or exclude specific bodies from the Paralympic movement [39,41,42].

Nevertheless, as Pronger [36] argues, because physical cultures, including sport, are essentially focused on the primordial sensuous, experiencing body, they can also reverse differentiation, by transgressing and diluting the divisive boundaries between culturally polarized bodies. A focus on the subjective experiences of diversely embodied individuals carries the potential to expose the fabrication of cultural truths on 'marginal' bodies. This has already been acknowledged regarding gender [43]; sexuality [44,45], race [46], humanness [47-49], and to some degree (dis)ability [5,50]. For this transgressive potential to be fully realized, postmodern sport needs to bring back what modern sport tried to keep out: the erotic pleasure of movement, a focus on the lived experience of the moving primordial body, "reasserting it as a being in its own right" [36] (p. 292).

In order to understand how ableism becomes imprinted in the cultural fabric of everyday life, we turn to Bourdieu's theory of practice. Bourdieu emphasizes the interdependency between embodied practices and the socio-cultural world, between the body as an object and the body as a subject. His theory shows how fabricated ideologies (such as ableism) reproduce themselves in cultural practices to the extent its logic becomes powerful because it is assumed to be 'natural'. To Bourdieu, the social world and individual bodies co-produce each other. Actors develop a certain 'habitus': generative schemes of perception, thought, and action [13] that strongly reflect the principles ruling the social landscapes in which they move and the social positions they occupy in these spaces. These stable dispositions materialize in embodied practical action, shaping the way individuals habitually speak, 
eat, dress, move, take care of their bodies, and present themselves. The symbiotic relationship between habitus and the social field, to use Bourdieusian nomenclature, is referred to as the "logic of practice" [13]. We contend that ableism constitutes a logic of practice because it expresses a stable convergence between habitus, habitual embodied social practices (interactions, physical environments, discourses), and its hegemonic premises (the able-bodied norm and the able/disabled constitutional divide). The socio-cultural world offers multiple examples of this logic [51]. For instance, the fact that wheelchair users are often pushed around by strangers, without their permission; or how most people assume they can run $100 \mathrm{~m}$ faster than an amputee Paralympian, just because they are 'able'. But, while it is important to connect ableism and practical action, the concept of habitus remains "within the limits of the embodied sedimentation of the social structures which produced it" [52] (p. 19). Even though Bourdieu accounts for agential possibilities [12,13], reproduction of a structuring and structural logic is more likely than its rupture within his practice theory.

To expand on the transformative potential of embodied practices, we engage with the pragmatic concept of 'situated action' [14]. Similar to habitus, situated action is grounded in the concept of bodily schemas, the set of ways in which individuals structure their bodily potentialities and dispositions. But rather than depending upon social conditioning, pragmatism conceptualizes bodily schemas as developing from the "internal dialogue (between the 'me' [the identity that others attribute to us] and the ' $\mathrm{I}$ ' [our subjective reflection on this identity])" and from the "raw" lived experience of embodied action as it deals with the contingent and continuous challenges of the external world [14] (p. 480). Thus, reproduction or/and change depend upon "practical efficacy as well as upon the individual's capacity to reflect on these circumstances" [14] (p. 481). As "people's belief in a given world and the efficacy of established ways of acting are repeatedly negated by lived experience" (author's italics) [14] (p. 479), thus change is an inevitable outcome.

Change is thus triggered by action informed by "crisis" and/or by action informed by "creative revelation" [14] (p. 481). When disruption occurs in the relationship between social norms, practical action, and personal reflection, a crisis originates, prompting individuals to consciously and actively question the logic and power of habitual action, often driven by ideologies such as ableism. This crisis may develop into creative revelation, action informed by an updated experiential knowledge about one's abilities. For instance, when an impaired athlete recognizes the invalidity of social expectations of diminished athletic abilities and realizes his/her strengths or when an able-bodied athlete loses a race against an impaired athlete and is forced to question his/her supposedly natural superiority. Crisis and creative revelation may foster new patterns of habitual action (habitus) [14].

Since an ableist logic of practice is unconsciously reproduced, the first step to challenge it is to facilitate situated actions that bring ableism into one's consciousness. For us, embodied action is the only possible entry point. That is, action in-formed by the body, both as object and subject [53]. Since the body is a psychological, cultural, social, as well as a material and biological identity it is "in lively interaction and in an ongoing dialogue with the world. The body in movement is not an object thing-body, but an experiencing and experienced unity connected to activity" [54] (p. 82). In the context of our research this means that SV participants not only use their bodies as tools to play a sport; they feel themselves moving while experiencing an array of sensuous happenings and they are able to reflect on the meanings of those experiences. This situation (may) make SV players aware of their unconscious bias and of how these contribute to shape power relations within and outside of the SV world.

Because hegemonic groups detain the power to legitimize and validate these truths, ableism transforms into a 'logic of practice' which inevitably shapes cultural habitus, expressed in all individual actions. As Bourdieu himself acknowledges, individual habitus and the social world are interdependent entities, therefore 'situated action' that repeatedly negates the validity of ableist premises does hold the potential to challenge and change such logic. As will become evident, SV offers a context for this potential to be ignited.

In the next section, we outline the cultural context of the parasport SV, before presenting our data in the ethnographic vignette. 


\section{The Physical Culture of Sitting Volleyball (SV)}

Sitting volleyball (SV) is a derivative of mainstream volleyball. According to De Haan [55], it was created in the 1950s within the military context, under the auspices of the Society of Dutch Military War Victims (BNMO), with a rehabilitation focus. The new practice combined elements of a popular German game, fistball, and of volleyball, a sport already established at the time. However, rather than jumping, running, and moving on their feet, SV players are required to move on their buttocks. "Sliding" rather than "sitting", would more accurately reflect this movement habitus. Since arms and hands are used to propel the body and perform the technical gestures, SV demands very fast transitions. To play the game proficiently, players need to make decisions, move, and intervene almost automatically. An elite player embodies this habitus at a pre-reflective level.

SV movement grammar attracts individuals whose impairment grants them speed of movement, while retaining coordination and upper body strength. Leg amputee players seem to be the perfect fit, evident at the elite level, however a diversity of impairments can be granted eligibility for competition. The classification process uses the level of amputation, muscle power, angular joint movement, and balance and/or coordination as criteria, rather than specific impairments. Athletes can be classified as minimally disabled (MD) (only two of these players are allowed on the court at any time) or disabled (D), with temporary or permanent status. While classification rules apply to all international competitions, within most nations (including Great Britain), competitive structures are inclusive (i.e., open to everyone), from people with no eligible impairments (labeled informally by the community as able bodied or $A B^{\prime}$ s) to more severely and diversely impaired participants.

SV was the first multi-impairment sport to be included in the Paralympics in 1980 (Arnhem), defying the Paralympics' medical organizational logic at the time, based upon types of impairment [56]. Within the Paralympic landscape, sitting volleyball was peripheral in two fundamental ways. First, it instituted sliding on the floor as acceptable, defying the ableist primacy of bipedal running and jumping as the athletic norm. Secondly, it proved that parasport can accommodate diverse impairments in the same activity, rather than following the same impairment-differentiation logic as that of medical institutions.

During 2006, fueled by the opportunities opened of London hosting the forthcoming 2012 Olympics and Paralympics, the national governing body for Volleyball, Volleyball England (VE), saw in sitting volleyball an opportunity to expand its relevance and prestige within the UK sporting landscape. Given the availability of Paralympic competitive places for the hosting nation, it was an ideal time to establish both a men's and women's national program. The development of the Great Britain teams up to a competitive standard in a relatively short timeframe seemed viable, considering the precarity of SV international development. The timing of the 2012 Paralympics led VE managers to quickly develop grassroot clubs, providing financial incentives for start-up; organizing and implementing a competitive structure; and training officials and volunteers. The primary goal was the competitive success of SV GB teams at the 2012 London Paralympic Games. Such developments materialized more clearly in the Autumn of 2009, at which point the first author was already participating as a player in one of the regional teams.

We now recreate the physical culture of SV, through an ethnographic creative non-fiction vignette.

\section{One Day in "Sliding Lives": A SV Grand Prix}

The ethnographic vignette below recreates one of the most significant events in the SV community; a National SV Grand Prix Tournament. These are one-day events (usually from 10 a.m. to 6 p.m.), in which all national SV teams gather to compete in two different tiers, according to their competitive level. The most fundamental elements of SV culture are apparent: first and foremost, the embodied experience of the game, but also its initial informality and amateurism; the nuanced complex dynamics of the interaction between diversely embodied participants, and the first author's positionality as an able-bodied ( $\mathrm{AB}$ ) participant/observer. This text must be understood as an analytical practice itself, yet one that invites the reader to actively reconstruct this lifeworld. It should be read with particular 
attention to signs of ableism implicit/explicit in the field's logic of practice as well as to situated actions that suggest critical disruptions regarding both the ableist norm and the able/disabled constitutional divide. The characters within the vignette are anonymized through pseudonyms.

Gosh, it's early. I can't complain considering that other participants left their homes at 5 a.m. Fortunately, my driver seems to be dealing with a 7 a.m. Sunday start much better than I am. Mike is in charge of organizing, setting up and managing the SV competitions. Since he lives nearby, in exchange for a lift, I am helping him getting things ready for the day. I met Mike through one of the local volleyball clubs, even before he started the SV group. He's a very well-respected volleyball player and coach. People seem to look up to him.

We arrive to the sports complex; the place is unsurprisingly still.

As Mike and I set up the nets and tape the lines on the courts, laugh, chat and banter start to fill in the atmosphere in the sports hall, against the soundscape of a dozen restless bouncing balls. A pair of worn-out jeans stands up against the closest wall, one of its legs skirted by a fancy training shoe. Next time I look, a beautiful Canadian leg joins in as the picture centerpiece. Mike tells me that both the men's and women's Canadian national teams are guests today.

Nearby, on the floor, chatting enthusiastically, Anderson and Kyle display a well-rehearsed routine: caressing the pink velvety texture of their exposed stumps with a eucalyptus scented cream, before slowly involving them with something similar to a very thick sock... The wounded fleshiness of their broken bodies overwhelms my senses. They proceed to expose their torsos shamelessly, before putting on their club shirts. Jason, just arrived, also gets rid of his cyborg legs, displaying his very short rosy stumps.

"Hey, have you considered washing your feet lately? We can barely breathe!" shouts Anderson, laughing, "And you're RUNNING late! If we don't win this weekend's tournament, it will be entirely your fault". Jason muffles a reply, limiting it to a cheeky smirk back.

The scenery changes rapidly. On the court to my right, some of my teammates run around showing off their volleyball skills. To the left, a chaotic agglomeration of bodiless legs of different sizes and models, wheelchairs, crutches, backpacks, balls, half-naked bodies, add to a scene reminiscent of a war zone. A few properly attired participants shuffle on their bottoms, mimicking the arbitrary dance of the yellow and blue flying balls. What the heck? this is the funniest trick!.. Jason, a double amputee, sits on the footrest of Danny's wheelchair. They are able to volley the ball to each other while Danny propels the wheelchair around...

Quite the prowess. . they're not alone in developing these circus-like skills. Elsewhere, Vera displays a string of impressive wheelies on Ellie's wheelchair. I would not dare, but Vera and Ellie are good friends.

As I am not playing this first round, I meander through the hall to take in all the sensuous splendor of the first competitions. On court $A$ and $B$, the first tier unfolds.

SMASH, dig and ... BONG! ... The ball falls flat just a meter in front of Mike, to his frustration.

"Ugghh! Come on! High ball, please!" Mike and the other 'Volleyball Owls', most of them able-bodied $(A B)$ volleyball players, struggle to reach the ball before it bounces on the floor.

Too many legs and not enough time", someone giggles. Mike does not find it funny. They lost a point.

On the far side of the court, Jason (double amputee) and Anderson (single amputee) move swiftly across the floor at admirable speed, whereas James pushes back on the floor with his strong arms, dragging behind his uncooperative legs. He's not quick enough this time. Wheeeeunuww! The referee points his hand to where the ball fell, this time on 'Flying Butts" side, just ahead of James.

"Unlucky, James," Janice says, patting him on the back.

Janice uses her full repertoire of volleyball skills to compensate for her teammate's inexperience. Usually this means being ready to cover the space around him. Moving forward is difficult for James, 
as he needs to carry the deadweight of his motionless legs. James had never played sport before his impairment, after a car hit him whilst cycling. Jason and Anderson started playing a couple of years ago, in the amputee's rehabilitation center following their military 'accidents'. Hannah, the only 'girl' in the team, also moves slowly and shyly, as if embarrassed by her congenital malformed lower limb extremities. The other 'Flying butts' do not seem to bother, as they usually send the ball 'over' her rather than 'to' her.

Avoiding receiving the serve, this time James places himself closer to the net with Jason, Anderson and Janice covering most of the court. Kyle, the tallest in the team, stretches his hands over the net to block the serve and cover the aerial space over James.

The strategy works. The serve reaches Janice, who skillfully passes to Kyle, setting for James to inflict the final smash with this powerful right arm.

"Arrrrrgggggg!", James puts all the frustration from the last point through the hit. The round yellow and blue mass hits the other side of the court almost instantaneously.

"AHHHH! YES!! What a killer!" shouts Anderson, with James disappearing under his teammates aggressive cheers!

On court $C$, the second competitive tier, an erratic rhythm unfolds. As the ball flies quite arbitrarily, the game is punctuated more by humorous banter than by skillful play, to the visible annoyance of referees. Most 'Sliding Rainbows' players smile, despite losing badly. Tom, whose muscular dystrophy appears to hinder his movements considerably, manages to punch the ball, torpedoing it to the opposition.

"Hooray ... Hurrah ... Yoohoo ... Two ... Three ... . RAINBOWWWWS!" shouts the whole team, in unison.

"Another 'scrappy' point", comments someone. "Doesn't matter. A point is a point."

Standing near the bench, Tom's parents keep clapping long after the end of the team's celebration, bursting with pride.

"That was cheeky, Tom...! Go on. . Take the ball then...," an opponent player returns the ball for the 'Sliding Rainbows' to serve, fanning displeasure.

The 'No Leg to Stand On' team (most players are amputees) look quite focused and determined to improve their game. They are learning the sport together, slowly and 'taking-the-mick-out' of each other. Most players joined the group following the advice of their physiotherapist at the local hospital. Their relational chemistry is obvious to everybody. Is this because they embody similar pains and challenges? They display a closeness I have not witnessed in other teams, even the most skillful ones. Roy, a former $(A B)$ volleyball player, leads and coaches the group.

"Hi, how are you?" This is Roger, according to many, the one person responsible for getting SV in GB off the ground.

"Wonderful, isn't it? You see all kinds of people coming together. There is no separation here. There is no us and them. We are all volleyballers!"

"It is pretty special, yes," I nod.

It is not the first time I have heard this mantra. Just earlier this morning, Mike was also telling me how SV is the most inclusive sport he knows.

"It's outrageous that the sport is so undermined. . Can you believe the other Paralympic athletes call us floor wipers?" continues Roger.

"I can see why... The floor looks pretty clean at the end of the day," I say, as I recall one of the male GB players telling a teammate that he would be relegated to the boccia team if he didn't 'man up'. Everybody laughed.

Opps ... My match is about to start. 
Wheeeuwwwwwww.... The referee starts the game. Here we go.

Hands on the floor. Hands up. Volley. Hands down. Feet push. Arms stretch forwards for a speedy dig. Uff... Feet soles down, hands down, push, slide, push, sliiiiidddeeeee. Breeеeеeaattheee. Vuummpppp ... Backwards, left, right ... Pushing, dig! Falling, straightening up, moving, falling... Right! Straight up! Breathe ... Breathe again ... end of rally ...

Drops of sweat run through my spine ... oh, it's hot! ... I volley the ball to the other side ... lose my balance... Back now! SMASHHHH! Arggggggggghhh! OUCHH! My NOSE! Arggggghhh!

I can't believe it. The pain humbles me! Neither my body nor my mind can keep up ... . Ta-thump ... ... ... . . . Ta-Thump ... Ta-Thump ... Ta-Thump, Ta-Thump! Stop, please! My heart threatens to jump out of my chest. Sitting???!! Disabled?! What?! Are you kidding?! Murder Volleyball! I'm knackered ....!

Wheeeuwwwwww! The final whistle is followed by a succession of hoorays! Some All Stars stand, some kneel, others use their stumps to get taller... .

"Why are they so happy anyway? Did they win the championship?" Gruntles my teammate Rebecca. Well, they are much bigger, and most are good standing volleyball players, after all. Is this fair?

As we queue up near the net to greet the opponents, I don't really know what to do. I remain seated and shuffle forward as I shake hands with the opponent team under the net. In the last Grand Prix, Kyle complained about how AB players stand up, walk, run and jump as they would do normally. "If this is sitting volleyball, why don't you just stay seated? Some of us do not have that opportunity of standing up and run..." So today, I slide ... to be willing to sit down seems important. As my friend Alice said, "when I sit down, I feel as if we are the same, whereas when I stand up, I feel different to them..."

"What's wrong with you? If you can stand up, why don't you? There is no need to pretend to be something you're not!" This time is John who doesn't agree with my greeting etiquette. Yes, at the end of the day, only some of us do have a choice to get up and walk home without using any paraphernalia. Well, it seems really difficult to get it right. What's the right thing to do or say? What a minefield!

\section{Who is (Dis)abled Anyway?}

Sitting down, bottom shuffling, sliding, falling, breathing heavily, sweating, swearing, cheering, mocking others, seeing, touching, feeling, and exploring one's own and other bodies opened endless subversive opportunities to question assumptions regarding (dis)ability. These are well documented in the vignette and an exhaustive analysis would undermine the readers' ability to identify these disruptive elements. Each reader's interpretation is dependent upon their own positionality regarding disability issues. To facilitate this process, we propose the following exercise: rereading the vignette, this time to identify ways in which the situated action of playing sitting volleyball may trigger moments of crisis and perhaps creative revelations vis-à-vis an old ableist logic of practice. Some analytical entry points may aid in this endeavor.

The clue is in the name: sitting volleyball. For most of us, sitting and volleyball constitutes an outright contradiction. This apparent paradox constitutes the first invitation to reflect differently about ability/disability. Are sitting and volleyball truly incompatible? What happens if a new normalcy is instituted? If instead of standing on two feet, we explore movement sitting down? After the initial resistance for fear of being associated with disability or being labeled as disabled, the simple willingness to take part in SV community already challenges one fundamental ableist assumption: that impairment equals unproductivity, passivity, dependency, sadness. And, by extension, that 'disability' sports are boring, easy, passive, and not fun at all. The physically challenging nature of the game, its fast-pace, its complex tactical and technical features, as well as the very intimate team cooperation are eye-opening for all participants, independent of their embodiment. One of the MD players, a former volleyball player did suggest "in many respects, this is a more aggressive game than volleyball. The opponents are closer, and so the battle is more intense". 
From the inside, SV is not a 'disabled' sport, rather an alternative physical culture, with a distinctive sporting habitus from mainstream sporting practices. As such, it has the power to disrupt an ableist logic. The context and rules of the game cause a cognitive dissonance against what has traditionally been accepted as the standard reference for athletic practices, the bipedal motion. Since the power of the norm depends on its invisibility as 'the natural order of things'; its simple recognition opened a way to challenge its validity.

Very soon after starting playing the game, the old norm started to make itself visible, creating some tensions and disruptions. For instance, regarding the extent to which the new movement habitus should be respected. In moments such as the formal greeting at the end of the game, or free time in between matches, participants who usually stood-up, walked, and ran tended to fall back into those behaviors. Even though new bodily hierarchies were created within the time/space of the SV match, the act of sitting down to play was seen as an important social leveler ("when I sit down, I feel as if we are the same; whereas when I stand up, I feel different ... "). SV participation thus created a new awareness of how context and movement habitus matter for one's perception of (dis)ability and equality.

Playing SV taught participants that there are alternative (to the norm), rather than inferior, ways of moving as well as different, rather than necessarily inferior, athletic bodies. Thus, another foundational ableist assumption to be repetitively disrupted early on through playing SV was that impairment equates to inferior performative abilities. This assumption is inherent to a socio-cultural understanding wherein impairment and disability are synonymous [18], known as the "medical model" of disability [57]. Related to this, the world paravolleyball classification regulations and practices, required to access international competitions, operate upon the premise that there are bodily distinctions significant enough to justify one's acceptance/exclusion from SV Paralympic competition [58]. Access to Paralympic competition is granted to those who, by virtue of their embodiment, would be in a position of unfair disadvantage in the mainstream sport context. More specifically, these regulations classify athletes competitive categories (MD and D) defined according to well-defined medical and functional criteria [59]. According to this system, players with leg amputations are assigned a D permanent status, whereas someone who has a foot amputation may be given a MD status. This is important because international regulations limit to two the number of MD players on the court any one time, making D players more 'valuable'. The inherent rationale to these regulations seems to be that the more impaired a player is, in reference to the abled normative body, the more limited sporting ability they are likely to have. Even though, as explicitly mentioned in the vignette, practice attests that "too many legs" may actually be a hindrance to the easiness of movement in SV.

The lure of Paralympic participation in the UK drove SV programs for people with impairments, and therefore classification practices were an imposition that ought to be observed. In the SV community articulated in the vignette, the assumption that impairment 'disables' was implicit for instance in the allocation of 'bonus points' to the teams who played with MD or D players (only in the buildup to London 2012). It is fair to conclude then, that formally, as an established international parasport, SV imposed a framework that exhibits an ableist logic. However, the grassroots context, at a regional and national level, where all embodiments were accepted, offered a fertile ground to challenge this logic. It can thus be argued that an ableist logic was both reinforced and challenged, within the UK SV community.

In light of Shilling's concept of situated practice, the experience of playing the sport seem to trigger moments of crisis, in that lived experience consistently negates old beliefs about impaired bodies and ability. The way SV destabilizes physical hierarchies based on the presumption that impairment automatically diminishes one's athleticism was consistently reported as one of its most empowering SV features in formal and informal interviews with SV players. One of the signs of this shift was that many D players started to display a different attitude towards their impairments: once hidden by most amputees, prosthetic legs started to be adorned and exposed as important to one's identity (cf. Figures 1 and 2). 


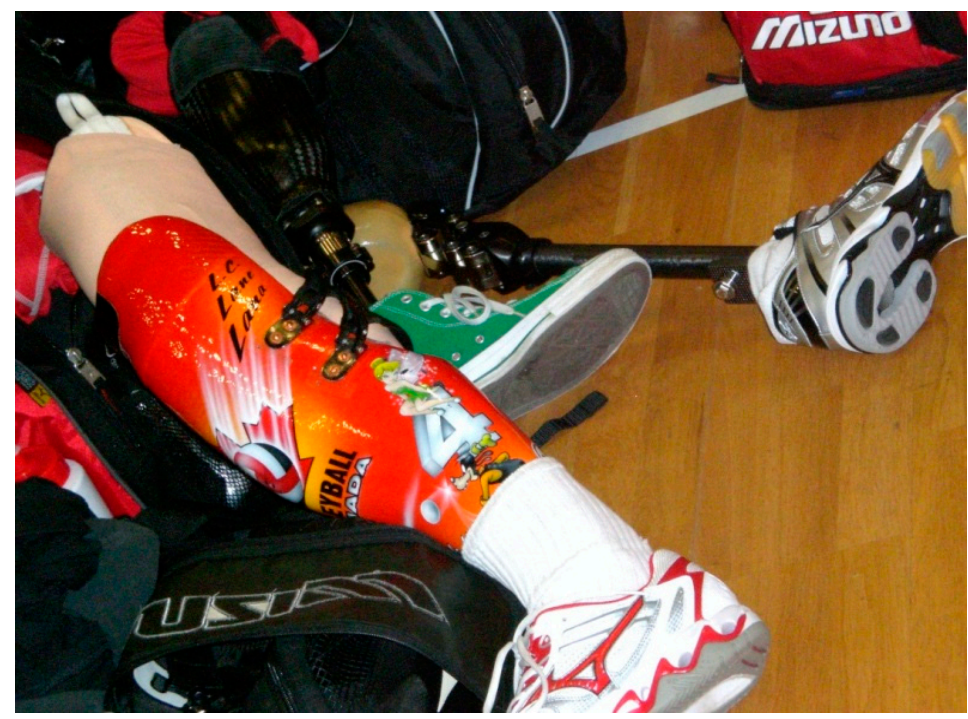

Figure 1. "I am a Canadian sitting volleyball (SV) player!" (C) P.David Howe.

As time passed by, feelings of embarrassment and attempts to disguise/hide impairment were replaced by increased acceptance and easiness with one's own body. The fleshy nature of impairment was constantly on display which weakened the stigma around it. People started to be confident enough to make fun of their own and other's embodiments. Showing off new tricks without hiding impairment, trying on each other's disability apparatuses, and openly talking about management strategies can be seen as a sign that the ableist norm started losing its grip. Impairment, its material and symbolic circumstances lost its taboo status because more positive meanings emerged in the process of being an athlete and playing SV.

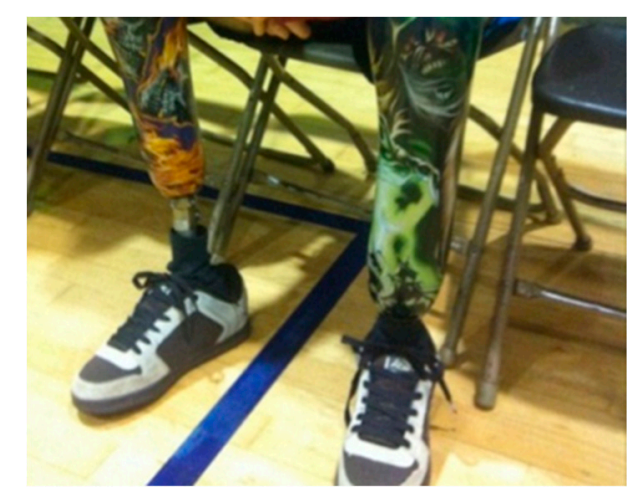

Figure 2. From hiding to "Showing Off" $\subset$ Carla Filomena Silva.

In SV, sporting movement norms were questioned because space was granted to explore alternative possibilities. SV offered practical opportunities to realize, in the form of lived experience, the narrowness of an ableist logic which presumes we need to stand on two feet to play sport. The subversive power of SV lies in its embodied nature. The situated action of playing the sport triggered so many moments of crisis and creative revelations, denying the legitimacy of an able-bodied norm in so many ways, that it led to a creative reframing of one's old assumptions on impairment and (dis)ability. Intimately associated with the acknowledgment and challenging of the power of the able-bodied norm in terms of the assumed athletic superiority of able-bodied players, the constitutional divide between the able and disabled (AB's and $\left.\mathrm{D}^{\prime} \mathrm{s}\right)$ was also questioned in and through SV. 


\section{8. "There Is Only Us: We Are All Volleyballers!"}

Knowing the productive possibilities of differently embodied individuals, rather than dwelling on their limitations was not a conscious choice in SV. Had it been conscious, the potential for critical disruption would have been curtailed by the influence of engrained stereotypes regarding impairment and disability. When playing, there was no opportunity for conscious judgment, beyond the urgent need to know how teammates and opponents responded to one's actions. What really mattered was to play well, in order to win the match. Differently embodied individuals were intimately bonded by the primary goal of winning, which prevented them from focusing their attention on individual difference.

Playing SV demonstrated experientially that perceiving oneself and others as fundamentally different based upon the level of impairment-based criteria, as suggested by classification practices, has little value beyond its formal use as an entry criterion into Paralympic sport. When SV is played (particularly at the grassroots level where diversity is greater), it inaugurates a shared field of potential movement interactions between and by discrete and diversely equipped bodies. The confines of the sport's regulations impose such a fast rhythm that each individual action must happen almost automatically. This means that, to be efficient, each action ought to be finely tuned with the teammates' and opponents' field of possibilities and the surrounding context. In order words, within a team, each player's body constitutes an extension of his/her teammates' bodies, such is the intimate collaboration demanded. It is simply impossible to play otherwise. The way Janice tries to 'cover' the space around James or how Kyle, the taller player, positions himself near the net to limit the direction of the opponent's serve to certain spaces, illustrate this dynamic. If these bodies were fundamentally different, such interactive field would not emerge.

Although competitive matches are central to the SV community, the whole spectrum of interactions in SV competitions/training significantly promoted the expansion of lived experiential knowledge on human embodiment. Despite everyone being informally labeled with a medicalized bodily category $(\mathrm{AB}, \mathrm{MD}$, and $\mathrm{D})$, the extensive opportunities to be, see, touch, interact, explore each other's physicality and reflect on the meanings of these experiences, exposed the conventional only nature of dividing labels. SV offered the clarity to see beyond the labels. As the vignette highlights, the exposure to rituals and routines of impairment care and disability management forced all individuals to expand their knowledge on (dis)ability, cutting through initial reactions of avoidance, fear, and perhaps even shock at the sight of the fleshy materiality of some of the impairments displayed. While amongst both players with and without impairments, feelings of discomfort were common initially, the quantity and quality of interactions in and out of the court cut through the veneer of the labeling to allow for deeper connections of empathy, care and friendship. The exacerbated self-perception of difference associated with possessing particular impairments, reported by many players, was diluted when sharing personal stories, revealing both common and unique features of one's life. Very soon, those stories and the 'otherness' of impairment and disability progressively faded out, as everyone started to be appreciated in his/her complexity and impairment accepted as only one component of such complexity. After a while, no story was overtly 'special', no impairment particularly inspirational, no difference so extraordinary as to allocate someone into anything but an SV player. Each individual experience of impairment and disability was unique but at the same time it could be or become anyone's story.

The transitory nature of ability became apparent in most accounts of acquired impairment. This constituted a significant learning for $\mathrm{AB}$ players. But equally, because all seemingly $\mathrm{AB}$ players shared their own struggles of physical pain, injury, and limitation, D players realized there is no such thing as absolute ability. Some AB players were quite 'disabled' by chronic injuries; some D players with above-the-knee amputations seemed advantaged in speed and balance; some D players with high amputations struggled to keep balance whereas an apparently severely disabled player (two legs and one arm amputated) showed great technical and athletic prowess. The end-product of being actively and performatively involved in SV was the creative revelation that the shared vulnerability inherent to our fleshy existence bind us together much more than the visible difference of physical impairment divides us. 
Playing the game in a context of such embodied richness allowed participants to witness and explore the depth and breadth of the vulnerability of all bodies. The repeated recognition of this shared vulnerability fundamentally denied the constitutional divide able/disabled. This realization was encapsulated in the slogan often articulated: "There is no us and them. There is only us". This statement of union reflects what seemed to be a genuine shift from a perception of divide implicit in the classification categories to an appreciation of the moral and human sameness connecting all participants.

\section{A Promising Starting Point to Challenge Ableism}

In a world so evidently ruled by an assumption of ableness based upon a non-impaired corporeal standard, we advocate for an exploration of the richness of our sensuous primordial embodied existence as a means to make visible the two fundamental pillars of ableism: the power of the able body norm (or 'normalcy') and the constitutional divide able/disabled. The disruptive potential of sporting practices to trigger cultural and social empowerment for people living with impairments takes central stage. However, as with any text, this paper can only offer a simplified version of reality that needs addressing in the form of a few caveats.

Because SV existence was residual prior to the timeframe addressed by this research, the event represented in the ethnographic vignette illuminates mainly a positive progression. When opportunities for individuals with impairments to explore their athleticism are limited, its very existence constitutes an improvement. However, ableist reminiscences were still present. The development of the SV Grand Prix series was not triggered by a sustained long-term will to expand grassroots opportunities for people with impairments but instead resulted from political opportunism for specific sporting institutions to benefit socially, culturally and financially from the eventual success of participation in the London 2012 Paralympic Games. This means SV was ruled and managed primarily by non-impaired individuals respected in volleyball cultures, with little personal or professional knowledge of impairment and/or disability. Knowledge of volleyball habitus was considered more important. This created physical hierarchies based upon the possession of volleyball capital, curtailing the political influence of most participants with impairments to shape SV culture. This hierarchy was more evident in teams with a higher competitive focus, while extended opportunities to learn from each other and to question old ableist assumptions were nourished in the groups where sociability was paramount.

Another important caveat relates to the intersection of disability with other relevant social categories, such as gender and class, to reduce or expand the power and status of individuals in SV. Although apparently opened to all, when playing the game, female participants were often purposely avoided in passages of play, perpetuating another set of harmful assumption regarding embodiment and physical performance which needs to be dismantled in both mainstream and parasport. The list of social categories intersecting with power in the SV context need to be expanded to include, type and form of impairment; age; volleyball knowledge, race, class and gender, for a more encompassing description/analysis. Yet, the expression and impact of some of these categories is still apparent in the ethnographic vignette.

\section{Conclusions}

If we could isolate one single factor responsible for the discrimination of people with disabilities in contemporary societies, that would be ableism. According to this logic, impaired bodies are, first and foremost, undesirable, unproductive, dependent, and tragic. These symbolic meanings more often than not foreground personal and social interactions [35]. But, as we have illuminated through the vignette in this paper, diversely embodied sporting cultures like SV offer an opportunity for all of us to question ableist logic.

Suspending such logic, SV opens endless opportunities to explore otherwise unlikely 'what ifs': What if the able-bodied person is now the disabled one and vice versa? What if we were unable to walk or run? Would this turn us into completely different people? What if the boundaries between ability 
and disability are more blurred than we have previously assumed? What if impairment is not so tragic? What if we focus on possibilities rather than on limits? On commonalities rather than differences?

SV is not a panacea to end ableism. Still, the practice of SV as outlined in the paper offers a critical lesson: the potential of embodied experiences to promote critical reflection and destabilize engrained ideologies such as ableism. While formally, SV largely reinforced the able norm and the dis/ability divide; at the level of practice, through embodied situated actions, these were questioned and revised by participants. The lived experience of interacting with diversely embodied teammates and opponents simply negated them. This type of knowledge is difficult to revert, as it derives from practical (in-the-body) knowledge, rather than from discursive rhetoric. The extent to which such an updated awareness of ableism materializes in improved attitudes and expansion of opportunities for people with impairments more widely is difficult to assess at this point. What is undeniable though is the importance of such an ideological awareness, the understanding of how embodiment intersects with both privilege and oppression.

To be more impactful parasport developments, like the SV community highlighted in this paper, need to consider a number of important factors. Increasingly culturally relevant research needs to be intersectional where (dis)ability is not seen insolation from age, class, gender, and race (among others). More detailed and nuanced understandings of the potential for new inclusive sporting and physical activity practices could be the outcome of a more intersectional driven agenda. We need this to gather a more inclusive understanding of human diversity. Furthermore, the advent of SV in the UK was the result of attempting to establish a legacy surrounding physical activity for impaired populations around the London 2012 Paralympic Games, but these initiatives should be designed with people with impairments central to decision making.

As we have shown through the research above, engaging with embodied diversity can be an eye-opening experience and have great pedagogical merit in teaching us all that human similarities far outweigh the differences.

Author Contributions: Conceptualization, C.F.S. and P.D.H.; methodology, C.F.S. and P.D.H.; software, C.F.S.; validation, C.F.S. and P.D.H.; formal analysis, C.F.S.; investigation, C.F.S.; resources, C.F.S. and P.D.H.; data curation, C.F.S.; writing - original draft preparation, C.F.S.; writing-review and editing, C.F.S. and P.D.H.; visualization, C.F.S. and P.D.H.; supervision, P.D.H.; project administration, C.F.S.

Funding: This research was funded by the Portuguese Foundation for Science and Technology.

Acknowledgments: We want to acknowledge the generosity, openness and trust of the sitting volleyball community. We hope this work may contribute to the improvement of movement opportunities for all.

Conflicts of Interest: The authors declare no conflict of interest.

\section{References}

1. Hoberman, J.M. Mortal Engines: The Science of Performance and the Dehumanization of Sport; Free Press: New York, NY, USA, 1992.

2. Girginov, V.; Parry, S.J.; Parry, J. The Olympic Games Explained: A Student Guide to the Evolution of the Modern Olympic Games; Routledge: London, UK; New York, NY, USA, 2005.

3. Campbell, F.K. Contours of Ableism: The Production of Disability and Abledness; Palgrave Macmillan: New York, NY, USA, 2009.

4. Howe, P.; Silva, C.F. The fiddle of using the Paralympic Games as a vehicle for expanding ability sport participation. Sport Soc. 2018, 21, 125-136. [CrossRef]

5. Silva, C.F.; Howe, P. The Social Empowerment of Difference: The Potential Influence of Para sport. Phys. Med. Rehabil. Clin. N. Am. 2018, 29, 387-408. [CrossRef]

6. Klein, A.M. Little Big Men: Bodybuilding Subculture and Gender Construction; State University of New York Press: Albany, NY, USA, 1993.

7. Howe, P.D. Sporting Bodies: Sensuous, Lived, and Impaired. In Companion to the Anthropology of Bodies/Embodiment; Mascia-Lees, F.E., Ed.; Wiley-Blackwel: Oxford, UK, 2011; pp. 102-116.

8. Howe, P.D. Reflexive ethnography, impairment and the pub. Leis. Stud. 2009, 28, 489-496. [CrossRef] 
9. Clayton, B. Ten minutes with the Boys, the thoroughly academic task and the semi-naked celebrity: Football masculinities in the classroom or pursuing security in a 'liquid' world. Qual. Res. Sport Exerc. 2010, 2, 371-384. [CrossRef]

10. Williams, T.; McGannon, K.R. Ethnographic creative nonfiction: Exploring the whats, whys and hows. In Ethnographies in Sport and Exercise; Routledge: London, UK, 2015; pp. 73-88.

11. Markula, P.; Denison, J. Moving Writing: Crafting Movement in Sport Research; Peter Lang: Bruxelles, Belgium, 2003.

12. Bourdieu, P. Outline of a Theory of Practice; Cambridge University Press: Cambridge, UK; New York, NY, USA, 1977.

13. Bourdieu, P. The Logic of Practice; Stanford University Press: Stanford, CA, USA, 1990.

14. Shilling, C. Physical capital and situated action:a new direction for corporeal sociology. Br. J. Sociol. Educ. 2004, 25, 473-487. [CrossRef]

15. Goffman, E. Stigma: Notes on the Management of Spoiled Identity; Prentice-Hall: Englewood Cliffs, NJ, USA, 1963.

16. Young, I.M. Justice and the Politics of Difference; Princenton University Press: Princeton, NJ, USA, 1990.

17. Vehmas, S.; Mäkelä, P. The ontology of Disability and Impairment: A Discussion of the Natural and Social Features; Kristiansen, K., Vehmas, S., Shakespeare, T., Eds.; Routledge: London, UK; New York, NY, USA, 2009; pp. 42-56.

18. Oliver, M. The Politics of Disablement; Macmillan Education: London, UK, 1990.

19. Davis, L.J. Enforcing Normalcy Disability, Deafness, and the Body; Verso: New York, NY, USA, 1995.

20. Mitchell, D.T.; Snyder, S.L. The Body and Physical Difference: Discourses of Disability; University of Michigan Press: Ann Arbor, MI, USA, 1997.

21. Snyder, S.L.; Mitchell, D.T. Cultural Locations of Disability; University of Chicago Press: Chicago, IL, USA, 2006.

22. Goodley, D. Dis/ability Studies: Theorising Disablism and Ableism; Routledge: London, UK; New York, NY, USA, 2014.

23. Davis, L. Disability Studies Reader; Routledge: London, UK; New York, NY, USA, 2017.

24. Finkelstein, V. Attitudes and Disabled People: Issues for Discussion; World Rehabilitation Fund: New York, NY, USA, 1980.

25. Shogan, D. The social construction of disability: The impact of statistics and technology. Adapt. Phys. Act. Q. 1998, 15, 269-277. [CrossRef]

26. Shogan, D. The Social Construction of Disability in a Society of Normalization; Steadward, R.D., GWheeler, D., Watkinson, E.J., Eds.; University of Alberta Press: Edmonton, AB, Canada, 2003; pp. 65-73.

27. Tremain, S. Foucault and the Government of Disability; University of Michigan Press: Ann Arbor, MI, USA, 2005.

28. Foucault, M. Madness and Civilization; 1961. Trans. Richard Howard; Random House: New York, NY, USA, 1965.

29. Foucault, M. The Birth of the Clinic: An Archaeology of Medical Perception; Tavistock: London, UK, 1973.

30. Foucault, M. Discipline and Punish: The Birth of the Prison; Pantheon Books: New York, NY, USA, 1977.

31. Foucault, M.; Gordon, C. Power/Knowledge: Selected Interviews and Other Writings, 1972-1977; Pantheon Books: New York, NY, USA, 1980.

32. Charlton, J. Nothing About Us Without Us: Disability Oppression and Empowerment; University of California Press: Berkeley, CA, USA, 2000.

33. Marks, D. Dimensions of Oppression: Theorising the embodied subject. Disabil. Soc. 1999, 14, 611. [CrossRef]

34. McRuer, R. Crip Theory: Cultural Signs of Queerness and Disability; NYU Press: New York, NY, USA, 2006.

35. Siebers, T. Disability Theory; University of Michigan Press: Ann Arbor, MI, USA, 2008.

36. Pronger, B. Post-sport: Transgressing boundaries in physical culture. In Sport and Post-Modern Times; State University of New York Press: New York, NY, USA, 1998; pp. 277-298.

37. Douglas, M. Natural Symbols: Explorations in Cosmology; Barrie and Rockliff: London, UK, 1970.

38. Murphy, R.F. Body Silent: The Different World of the Disabled; H. Holt: New York, NY, USA, 1990.

39. Howe, P.D. The Cultural Politics of the Paralympic Movement; Routledge: London, UK; New York, NY, USA, 2008.

40. Purdue, D.E.J.; Howe, P.D. Who's in and who is out? Legitimate bodies within the Paralympic Games. Sociol. Sport J. 2013, 30, 24-40. [CrossRef]

41. Howe, P.D.; Jones, C. Classification of disabled athletes: (Dis)empowering the paralympic practice community. Sociol. Sport J. 2006, 23, 29-46. [CrossRef] 
42. Jones, C.; David Howe, P. The Conceptual Boundaries of Sport for the Disabled: Classification and Athletic Performance. J. Philos. Sport 2005, 32, 133-146. [CrossRef]

43. Messner, M. Power at Play: Sports and the Problem of Masculinity; Beacon Press: Boston, MA, USA, 1995.

44. Anderson, E. Inclusive Masculinity: The Changing Nature of Masculinities; Routledge: London, UK; New York, NY, USA, 2010.

45. Cahn, S. Coming on Strong: Gender and Sexuality in Women's Sport; University of Illinois Press: Urbana, IL, USA, 2015.

46. Hylton, K. Race and Sport: Critical Race Theory; Routledge: London, UK; New York, NY, USA, 2008.

47. Butryn, T.M.; Masucci, M.A. Traversing the matrix: Cyborg athletes, technology, and the environment. J. Sport Soc. Issues 2009, 3, 285-307. [CrossRef]

48. Norman, M.E.; Moola, F. 'Bladerunner or boundary runner'?: Oscar Pistorius, cyborg transgressions and strategies of containment. Sport Soc. 2011, 14, 1265-1279. [CrossRef]

49. Swartz, L.; Watermeyer, B. Cyborg anxiety: Oscar Pistorius and the boundaries of what it means to be human. Disabil. Soc. 2008, 23, 187-190. [CrossRef]

50. DePauw, K.P. The (1n) visibility of disability: Cultural contexts and sporting bodies. QUEST 1997, 49, 416-430. [CrossRef]

51. Morris, J. Pride Against Prejudice: A Personal Politics of Disability; Women's Press: London, UK, 1991.

52. Bourdieu, P.; Wacquant, L.J.D. An Invitation to Reflexive Sociology; University of Chicago Press: Chicago, IL, USA, 1992.

53. Merleau-Ponty, M. Phenomenology of Perception; Humanities Press: New York, NY, USA, 1962.

54. Duesund, L. Who is moving my body when I am moving? A phenomenology of adapted physical activity. Sobama J. 2007, 12, 80-87.

55. De Haan, J. Sitting Volleyball; Uitgeverij De Vrieseborch: Den Haag, The Netherlands, 1986.

56. Bailey, S. Athlete First: A History of the Paralympic Movement; John Wiley \& Sons: Chichester, UK; Hoboken, NJ, USA, 2008.

57. Shakespeare, T. Disability Rights and Wrongs. Beyond Discip. 2008, 4, 45.

58. WOVD (World Organisation of Volleyball for the Disabled). Official Sitting Volleyball Rules 2009-2012; FIVB: Lausanne, Switzerland, 2009.

59. WOVD. Medical and Functional Classification Handbook (Medical Handbook); FIVB: Lausanne, Switzerland, 2009. 